\title{
Effects of Microstructural Modification Using Friction Stir Processing on Fatigue Strength of Butt-Welded Joints for High-Strength Steels
}

\author{
Hajime Yamamoto*, Kazuhiro Ito \\ Joining and Welding Research Institute, Osaka University, Osaka, Japan \\ Email: ^h.yamamoto@jwri.osaka-u.ac.jp
}

How to cite this paper: Yamamoto, H. and Ito, K. (2018) Effects of Microstructural Modification Using Friction Stir Processing on Fatigue Strength of Butt-Welded Joints for High-Strength Steels. Materials Sciences and Applications, 9, 625-636.

https://doi.org/10.4236/msa.2018.97045

Received: May 2, 2018

Accepted: June 25, 2018

Published: June 28, 2018

Copyright (C) 2018 by authors and Scientific Research Publishing Inc. This work is licensed under the Creative Commons Attribution International License (CC BY 4.0).

http://creativecommons.org/licenses/by/4.0/

\begin{abstract}
Friction stir processing (FSP) is an effective surface-microstructure modification technique using a rotational tool to refine and homogenize microstructure of metallic materials. In this study, FSP was conducted on the surface of the heat-affected zone (HAZ), which is a region exhibiting degraded mechanical properties and shown to have microstructural changes, of butt-welded joints for two high-strength steels with tensile strength grades of $490 \mathrm{MPa}$ and $780 \mathrm{MPa}$ (hereafter HT490 and HT780, respectively). Inhomogeneous mixing of materials derived from weld metals and base metals (BMs) in a stir zone (SZ) produced inhomogeneous distribution of elements and microstructure depending on the set of the advancing side and retreating side in the SZs. The welded joints with FSP for HT490 exhibited higher hardness than that of the $\mathrm{BM}$ through whole of the SZ surface (fine polygonal ferrite grains and bainite structure with laths at the $\mathrm{Mn}$-rich and $\mathrm{Mn}$-poor regions, respectively). On the other hand, those for HT780 exhibited the minimum hardness value similar to that of the BM at the SZ surface (a few polygonal ferrite grains in the matrix of martensite laths). Fatigue strength increased by about $35 \mathrm{MPa}$ and $15 \mathrm{MPa}$ in stress amplitude at $10^{7}$ cycles as fatigue limit due to FSP. Fatigue failure occurred at the BM and the SZ, respectively, in the welded joints modified by FSP for HT490 and HT780, in comparison with the HAZs in the as-welded joints for both grade steels. The difference in fatigue strength increase due to FSP and failure location between the welded joints for HT490 and HT780 can be attributed to the topmost SZ microstructures and their distribution.
\end{abstract}

\section{Keywords}

Friction Stir Processing (FSP), High-Strength Steel, Fatigue Strength, Grain Refinement, Post-Weld Treatment 


\section{Introduction}

Friction stir processing (FSP), which is based on the principle of friction stir welding, is an effective surface-modification technique using a rotational tool to refine and homogenize microstructure of various metallic materials [1]. FSP can locally produce a stir zone (SZ) with higher mechanical properties such as strength, ductility and fracture toughness in comparison with the base metal (BM) [2]-[7]. Furthermore, material flow during FSP contributes to the improvement of fatigue property of cast alloys [8] [9]. This can be explained by elimination of internal defects and coarse precipitates that can act as fatigue crack initiation sites in addition to grain refinement.

Recently, FSP has been also applied to fusion welds as post-weld treatment. For example, Costa et al. [10] [11] [12] [13] reported that grain refinement and stress concentration reduction due to FSP at the weld toe increased fatigue strength of several aluminum alloy joints fabricated by metal inert gas welding. FSP can be used as a new technique to increase fatigue strength of the fusion-welded joints, and provide advantages different from grinding [14] [15] [16] and remelting [17] [18] [19] for the weld geometry modification or peening [20] [21] [22] and post-weld heat treatment [23] for decreasing tensile residual stress. However, use of the FSP technique has been limited to a few light metal alloy welds so far. On the other hand, FSP might possibly be useful for modifying soft or brittle microstructures related to phase transformation in the heataffected zone (HAZ) in the steel joints, and it is essential to understand fatigue property of joints with the topmost SZ microstructure mixed with the BMs and weld metals (WMs) at the prior HAZ.

We have reported that application of FSP on the topmost layer of tungsten inert gas (TIG) welds on SS400 mild steel plates could increase bending fatigue strength [24]. Significant grain refinement in the SZ of the topmost layer on the weld bead surfaces was observed, and it could be a reason for the increased fatigue strength. In the present study, FSP was conducted on the HAZ surface of butt-welded joints for two high-strength steels with $490 \mathrm{MPa}$ and $780 \mathrm{MPa}$ in tensile strength grades (hereafter HT490 and HT780, respectively), and the effects on microstructure and fatigue strength were investigated.

\section{Experimental Procedures}

Double-sided $\mathrm{CO}_{2}$ gas butt-welding on square groove was conducted on 4.5mm-thick HT490 and HT780 plates using MX-Z200 and DW-A80L filler metals, respectively. The chemical compositions of these plates and filler metals are shown in Table 1. After removing excess WMs by grinding, double-sided TIG welding was conducted on the weld beads produced by $\mathrm{CO}_{2}$ gas welding. $\mathrm{CO}_{2}$ gas welding and TIG welding were operated under the conditions as shown in Table 2.

Double-sided FSP was performed on the surface of four fusion lines in Ar atmosphere. A WC-6\%Co tool having a 12-mm-diameter shoulder and 0.8-mm- 
Table 1. Chemical compositions of BM and filler metal for the welded plates (unit mass\%).

\begin{tabular}{ccccccccccccccc}
\hline \multicolumn{2}{c}{ Materials } & $\mathrm{C}$ & $\mathrm{Si}$ & $\mathrm{Mn}$ & $\mathrm{P}$ & $\mathrm{S}$ & $\mathrm{Cu}$ & $\mathrm{Ni}$ & $\mathrm{Cr}$ & $\mathrm{Mo}$ & $\mathrm{V}$ & $\mathrm{Al}$ & $\mathrm{Fe}$ & $\mathrm{C}_{\text {eq }}$ \\
\hline HT490 & $\mathrm{BM}$ & 0.14 & 0.23 & 1.08 & 0.014 & 0.006 & 0.01 & 0.01 & 0.02 & - & 0.002 & 0.028 & $\mathrm{Bal}$. & 0.33 \\
& Filler metal & 0.03 & 0.55 & 1.55 & 0.011 & 0.007 & 0.02 & 0.01 & 0.02 & $<0.01$ & $<0.01$ & - & Bal. & 0.3 \\
HT780 & BM & 0.11 & 0.26 & 0.8 & 0.008 & 0.001 & 0.18 & 0.79 & 0.45 & 0.44 & 0.04 & - & Bal. & 0.49 \\
& Filler metal & 0.06 & 0.31 & 1.9 & 0.008 & 0.007 & - & 2.48 & 0.02 & 0.14 & $<0.01$ & - & Bal. & 0.58 \\
\hline
\end{tabular}

Table 2. Process parameters of $\mathrm{CO}_{2}$ gas welding and TIG welding.

\begin{tabular}{cccccc}
\hline \multirow{2}{*}{ Welding processes } & Welding current, & Arc voltage, & Welding speed, & Arc tilt angle, & Arc length, \\
\cline { 2 - 6 } & $I / \mathrm{A}$ & $V / \mathrm{V}$ & $V / \mathrm{mm} / \mathrm{min}$ & $\theta\left(^{\circ}\right)$ & $L / \mathrm{mm}$ \\
\hline $\mathrm{CO}_{2}$ gas welding & 330 & 31 & 900 & -40 & 15 \\
TIG welding & 180 & 13 & 50 & 5 & 2 \\
\hline
\end{tabular}

long and 4-mm-diameter probe was inclined at $3^{\circ}$ and operated at a travel speed of $140 \mathrm{~mm} / \mathrm{min}$ in the welding direction with a counter-clockwise rotation at a rotational speed of $400 \mathrm{rpm}$ with $14.7 \mathrm{kN}$ in applied stress control [24].

Microstructure of the specimens obtained from the joints was observed by optical microscopy (OM) and scanning electron microscopy (SEM). A cross section of the specimens after mechanical polishing was etched with $2 \%$ nital solution for these observations. Main elements of the BM and filler metal were analyzed by electron probe microanalyzer (EPMA) equipped with SEM.

Vickers hardness tests were performed at room temperature (RT) on the cross section with an applied load of $1.96 \mathrm{~N}$ and loading time of $35 \mathrm{~s}$. Tensile fatigue tests were performed at RT with a sinusoidal waveform of $20 \mathrm{~Hz}$ as a function of maximum applied stress with a stress ratio of 0.1 . The shape and size of the specimens prepared using electrical discharge machine are shown in Figure 1. The gauge section contains the BMs, HAZs and WMs with and without FSP-modified regions. The specimen surfaces were smoothed by mechanical polishing to eliminate stress concentration regions before the testing to focus on the effects of microstructural modification on the fatigue strength.

\section{Results and Discussion}

Figure 2 shows cross-sectional OM images of microstructure beneath the surface of the as-welded joints for HT490 and HT780. The BMs of HT490 and HT780 exhibited ferrite-pearlite structure and tempered martensite structure, respectively. The WMs mainly consisted of acicular ferrite structure, with the finest grains in the both grade as-welded joints. The HAZs of about 1 to $2 \mathrm{~mm}$ in width formed in the vicinity of WMs. Pearlite globalization and tempering occurred in intercritical HAZ (ICHAZ) of HT490 and HT780, respectively. Microstructure changes between fine-grained HAZ and coarse-grained HAZ (CGHAZ) were attributed to recrystallization or phase transformation for ferrite grains. 


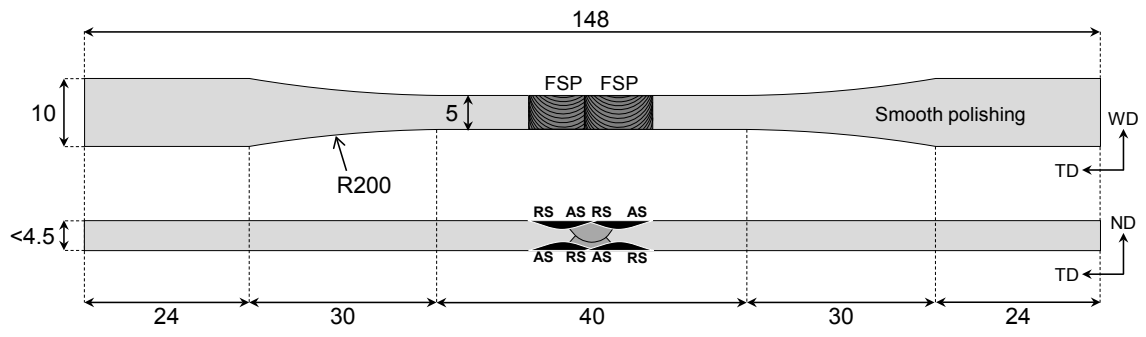

Figure 1. Schematic illustration of a fatigue specimen ( $\mathrm{mm} \mathrm{scale)}$.

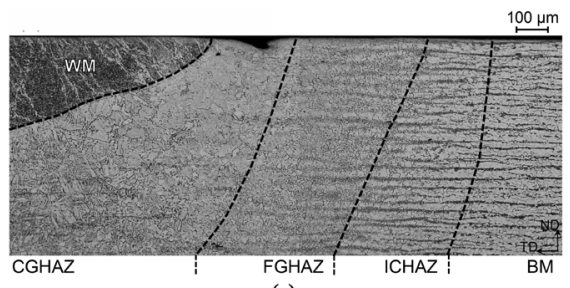

(a)

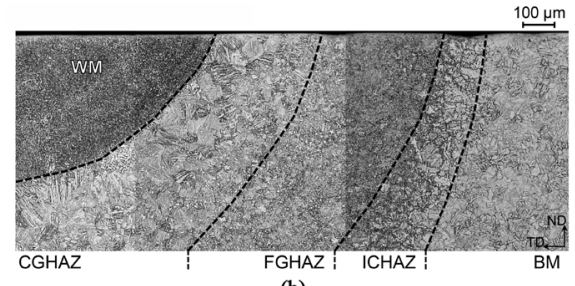

(b)

Figure 2. Cross-sectional OM images of microstructure in the as-welded joints for (a) HT490 and (b) HT780, respectively. (a) As-welded HT490; (b) As-welded HT780.

Figure 3 shows cross-sectional OM images of the welded joints for HT490 and HT780 with and without FSP. The bead width in both as-welded joints was about $8 \mathrm{~mm}$ (Figure 3(a) and Figure 3(c)). FSP conducted along HAZs to modify the topmost microstructure, resulting in formation of the SZ without a defect of about 1 to $2 \mathrm{~mm}$ in depth and about $10 \mathrm{~mm}$ in width. The BMs and WMs were not homogeneously mixed in the SZ; the materials in the prior WM were worn away on the advancing side (AS) and segregated beneath the surface, while materials in the prior WM remained and spread in the BM region on the retreating side (RS), depending on the tool rotation. To understand material plastic flow caused by FSP, elemental analysis using EPMA was conducted. Figure 4 shows EPMA mappings of $\mathrm{Mn}$, which is an element with large content difference between the BM and filler metal, in the welded joints for HT490 and HT780 modified by FSP. A color change from blue to red indicates an increase in $\mathrm{Mn}$ content. The WMs had higher Mn content than that of the BMs in both grade steels. Plastic flow due to FSP did not mix the BMs and WMs homogeneously, resulting in uneven separation of mainly two regions with $\mathrm{Mn}$-rich (green) and Mn-poor (blue) regions in the SZ. The material of the WM flowed into the BM in sharp-edge shape on the RS in the right-hand upper side SZ (the set on RS in the prior WM and AS in the prior BM) in both grade of steels. EPMA point analyses confirmed that the green region on the RS of the SZ exhibited a little lower content (1.53 and 1.48 mass\% in Figure 4(a) and Figure 4(b), respectively) than the initial WM (1.74 and 1.58 mass\% in Figure 4(a) and Figure 4(b), respectively) and blue region in the SZ exhibited a little higher Mn content (1.18 and 0.96 mass\% in Figure 4(a) and Figure 4(b), respectively) than that of the initial BM (1.08 and 0.86 mass\% in Figure 4(a) and Figure 4(b), respectively). This suggests that the mixing of WMs and BMs took place not homogeneously but quite partially in the SZ. The Mn-content separation due to inhomogeneous 


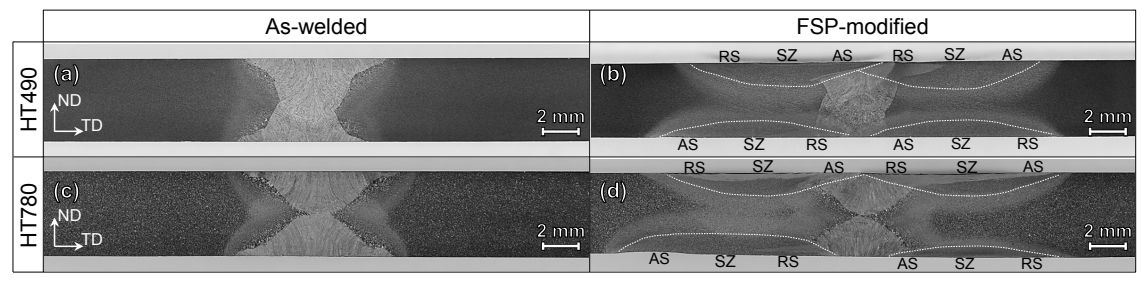

Figure 3. Cross-sectional OM images of the welded joints (a), (c) w/o and (b), (d) w/FSP for (a), (b) HT490 and (c), (d) HT780.
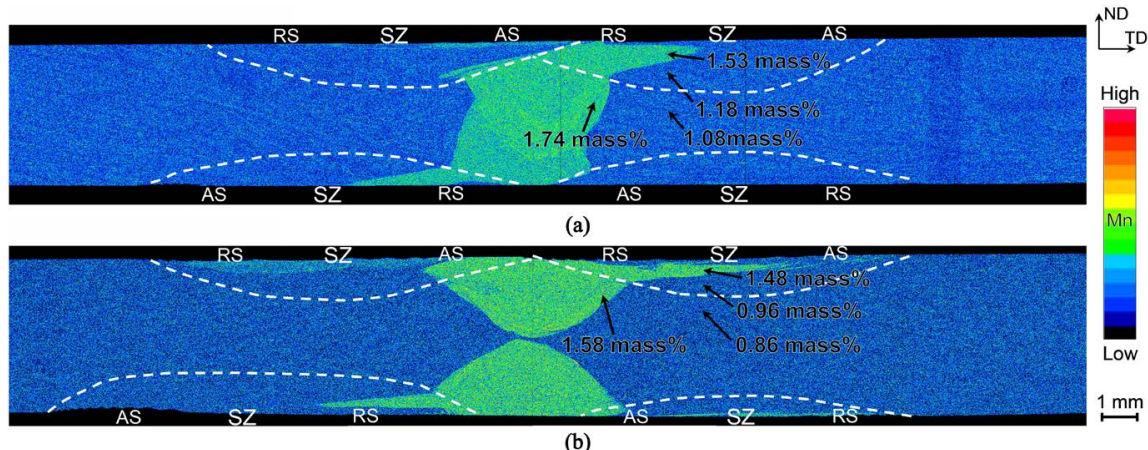

(b)

Figure 4. EPMA mappings of $\mathrm{Mn}$ of the welded joints with surface microstructure modified by FSP for (a) HT490 and (b) HT780, together with Mn contents at the positions pointed by arrows. (a) FSP-modified HT490; (b) FSP-modified HT780.

mixing was also observed in the left-hand upper side SZ (the set on AS in the prior WM and RS in the prior BM) of both grade steels, but it is not similar and Mn content separated roughly up and down resulting in higher Mn-content regions segregated beneath the surface. The difference of $\mathrm{Mn}$-content distributions between the different sets on AS and RS in the SZ is dependent on the tool rotation, and corresponds to contrast difference in the SZ in Figure $3(\mathrm{~b})$ and Figure $3(d)$. The partial mixing with sharp-edge shape of the green region in the SZ was shorter-ranging and wider-ranging, respectively, in the vertical and horizontal directions in HT780 than in HT490 (the set on RS in the prior WM and AS in the prior BM), while that of Mn segregation beneath the surface was more in HT780 than in HT490 (the set on AS in the prior WM and RS in the prior BM).

Figure 5 shows cross-sectional OM and SEM images beneath the surface of the welded HT490 and HT780 joints modified by FSP. FSP provided significant grain refinement beneath the surface. However, the SZ possessed both Mn-rich (more material from the prior WM) and Mn-poor (more material from the prior BM) with bright and dark contrasts, respectively (Figure 5(a) and Figure 5(b)). Fine polygonal ferrite grains (Figure 5(c)) and bainitic ferrite grains with laths (Figure 5(d)) were observed in the Mn-rich and Mn-poor regions in the SZ of HT490, respectively. On the other hand, Mn-rich regions in the SZ of HT780 exhibited duplex structure consisting of martensite laths and polygonal ferrite grains and its Mn-poor regions exhibited full martensite structure, as shown in Figure 5(e) and Figure 5(f), respectively. Although the Mn-rich regions could 
more easily exhibit bainite or martensite structures than the Mn-poor regions in terms of carbon equivalent $\left(\mathrm{C}_{\mathrm{eq}}\right)$, in fact, it allowed polygonal ferrite formation. This can be explained by the difference in prior austenite grain size. Initial microstructure of the WM was finer than that of the BM. This trend should remain after austenitic phase transformation during FSP. Therefore, ferrite formation during the cooling time could easily occur from the fine austenite grains in the $\mathrm{Mn}$-rich regions consisting of materials mainly from the prior WM.

Figure 6 shows Vickers hardness mappings beneath the surface of the welded joints for HT490 and HT780 with and without FSP. A color change from blue to red indicates an increase in hardness. Average values of BMs hardness of HT490 and HT780 were about $170 \mathrm{HV}$ and $280 \mathrm{HV}$, respectively. The ICHAZ exhibited the lowest hardness in both grade as-welded steel joints. In contrast, the highest hardness region was observed at the WM in HT490 and CGHAZ in HT780, which exhibited acicular ferrite structure and martensite structure, respectively. In HT490, although heterogeneous Mn distribution and OM-image contrast were observed in the SZ (the set on RS in the prior WM and AS in the prior $\mathrm{BM}$ ), grain refinement provided by FSP increased hardness homogeneously beneath the surface. Hardness of the Mn-rich region (about $200 \mathrm{HV}$ ) exhibiting the fine polygonal ferrite grains in the SZ was higher than that of the BM, but slightly lower than that of the Mn-poor region (about $230 \mathrm{HV}$ ). On the other hand, the large hardness difference among the WM, HAZs, and BMs was observed at the surface of the as-welded joints for HT780 (about 230 and $380 \mathrm{HV}$ for ICHAZ and CGHAZ, respectively). The difference was disappeared and averaged after surface microstructure modification provided by FSP. Most of the SZ regions exhibited the highest hardness of about $420 \mathrm{HV}$ with full martensite structure, while the topmost layer possessed hardness of $280 \mathrm{HV}$ (similar to that of the BM) with the polygonal ferrite grains in addition to martensite laths, and was dispersed thin through whole of the SZ surface. Therefore, hardness increase beneath the joint surface due to microstructure modification provided by FSP had a great impact for HT490 than for HT780.

Effect of the surface microstructure modification provided by FSP on fatigue performance was investigated in the welded joints for HT490 and HT780, and the relationship between the applied stress amplitude and number of cycles to failure (S-N diagram) is shown in Figure 7, together with those of the as-welded specimens. Fatigue life of the welded joints modified by FSP ( 0 , solid line) was longer than that of the as-welded joints $(\Delta$, broken line) at every applied stress amplitude for both HT490 and HT780. The stress amplitude without failure at $10^{7}$ cycles (arrows) was estimated at about $180 \mathrm{MPa}$ and $145 \mathrm{MPa}$ as fatigue limit with and without FSP for HT490, respectively, and similarly about $195 \mathrm{MPa}$ and 180 $\mathrm{MPa}$ for HT780. The stress amplitude due to FSP increased to about $35 \mathrm{MPa}$ and $15 \mathrm{MPa}$ at HT490 and HT780, respectively. Thus, FSP can be concluded as an effective technique to increase fatigue strength of the welded joints for both HT490 and HT780, although the former increase was larger than the latter. 


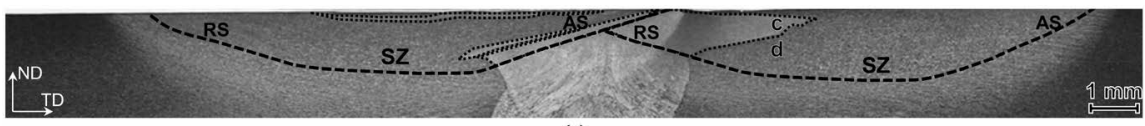

(a)

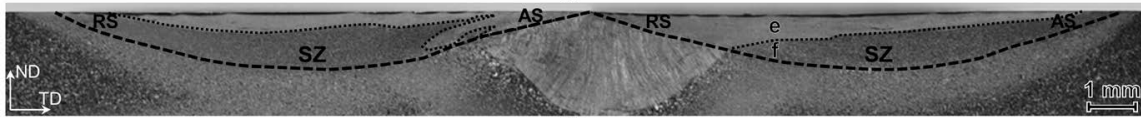

(b)

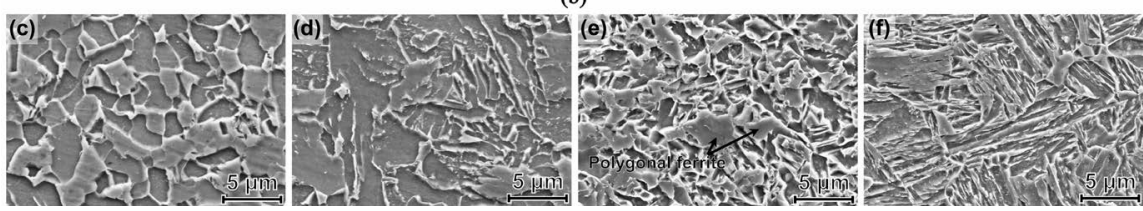

Figure 5. Cross-sectional OM images beneath the surface of the welded joints with surface microstructure modification by FSP for (a) HT490 and (b) HT780, and (c)-(f) SEM images around the points shown by c-f in (a) and (b). (a) FSP-modified HT490; (b) FSP-modified HT780.

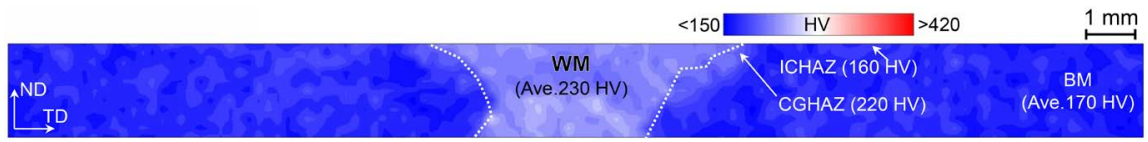

(a)

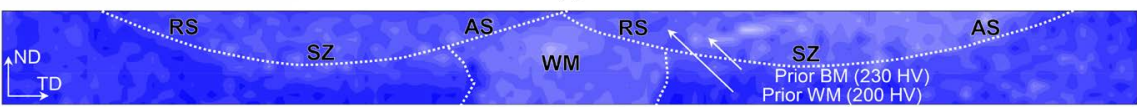

(b)

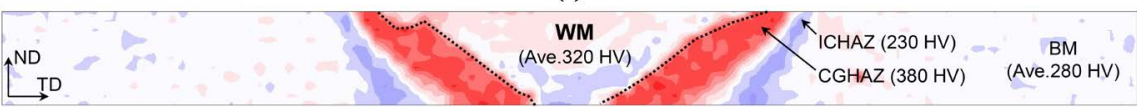

(c)

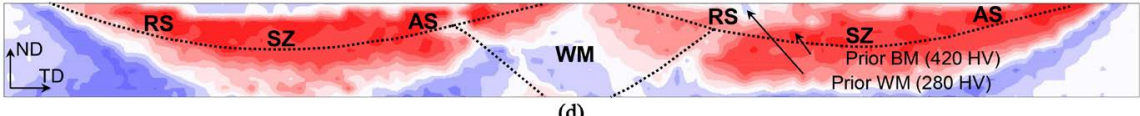

(d)

Figure 6. Vickers hardness mappings of the welded joints (a), (c) w/o and (b), (d) w/FSP for (a), (b) HT490 and (c), (d) HT780. (a) As-welded HT490; (b) FSP-modified HT490; (c) As-welded HT780; (d) FSP-modified HT780.

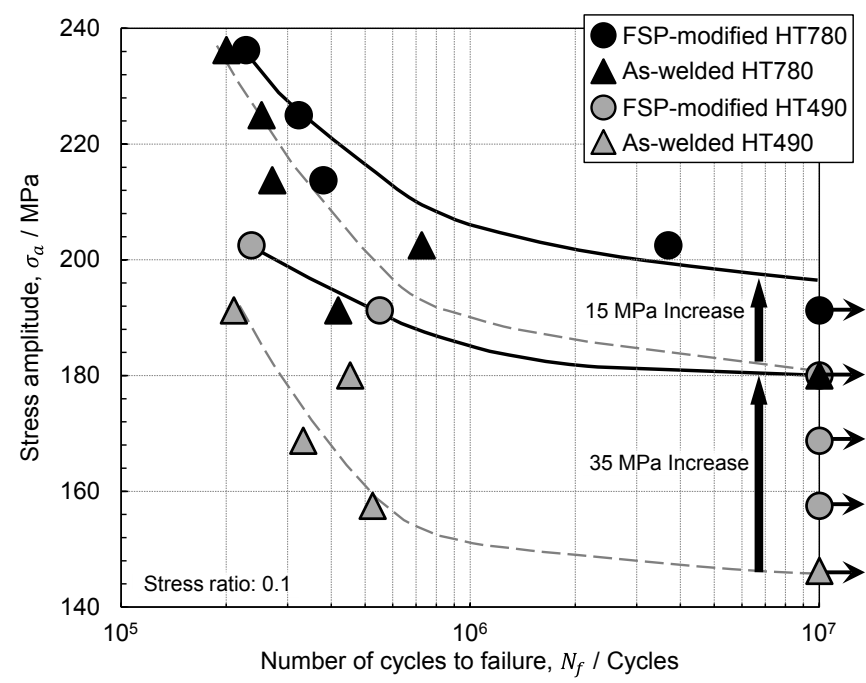

Figure 7. S-N curves of the welded joints w/o and w/FSP for HT490 and HT780 obtained in the four-point bending fatigue tests. 
To clarify the fatigue failure location, OM and SEM observations were conducted at a corresponding cross section of the welded joints with and without FSP for both grade steels. Failure locations of all specimens after four-point bending fatigue tests are indicated in Table 3 , and the typical OM and SEM images are shown in Figure 8 and Figure 9. Fatigue failure occurred mostly at ICHAZ with the lowest hardness and occasionally at CGHAZ for HT490 (Figures 8(a)-(d)), and at CGHAZ with the highest hardness for HT780 in the as-welded joints (Figure $8(\mathrm{~g})$ and Figure $8(\mathrm{~h})$ ). On the other hand, fatigue failure occurred at the BM of the welded joint with FSP for HT490 (Figure 8(e) and Figure 8(f)), suggesting that fatigue resistance would be higher in the SZ than that in the BM. In contrast, it occurred at the SZ of the welded joint with FSP for HT780 (Figure 8(i) and Figure 8(j)), suggesting that fatigue resistance of the SZs would be similar or lower than that of the BM. This is in good agreement with formation of thin layers with hardness of $280 \mathrm{HV}$ similar to that of the BM through whole of the SZ surface with the polygonal ferrite grains in addition to martensite laths.

Fatigue crack beneath the surface initiation site in the SZs surface for HT780 seems to change the propagation direction frequently at the grain boundaries (Figure 9(b)) in comparison to that of the CGHAZ as shown in Figure 9(a). Grain refinement provided by FSP could contribute to increase resistance to fatigue crack propagation. However, the presence of thin layers with hardness of $280 \mathrm{HV}$ partly with ferrite grains at the SZ surface facilitated fatigue crack initiation resulting in hardness decrease. The fatigue cracks were reported to easily initiate in ferrite grains or at ferrite/martensite interface in duplex ferrite-martensite structure [25]. Thus, the difference of fatigue strength increase and the failure location due to FSP between HT490 and HT780 can be attributed to the topmost SZ microstructures and their distribution.

\section{Conclusions}

FSP was conducted on the HAZ surface of butt-welded joints for HT490 and HT780. Grain refinement due to FSP can be concluded to be an effective technique to increase the fatigue strength. The difference in fatigue strength increase due to FSP and failure location between the welded joints for HT490 and HT780 can be attributed to the topmost SZ microstructures and their distribution. The important findings are as follows:

1) Inhomogeneous mixing of materials derived from the WMs and BMs in the SZs produced inhomogeneous distribution of elements and microstructure depending on the set on AS and RS in the SZs. The Mn-rich and Mn-poor regions were observed beneath the surface of the welded joints. They were, respectively, fine polygonal ferrite grains and bainite structure with laths for HT490, and a few polygonal ferrite grains in the matrix of martensite laths and full martensite structure for HT780. 

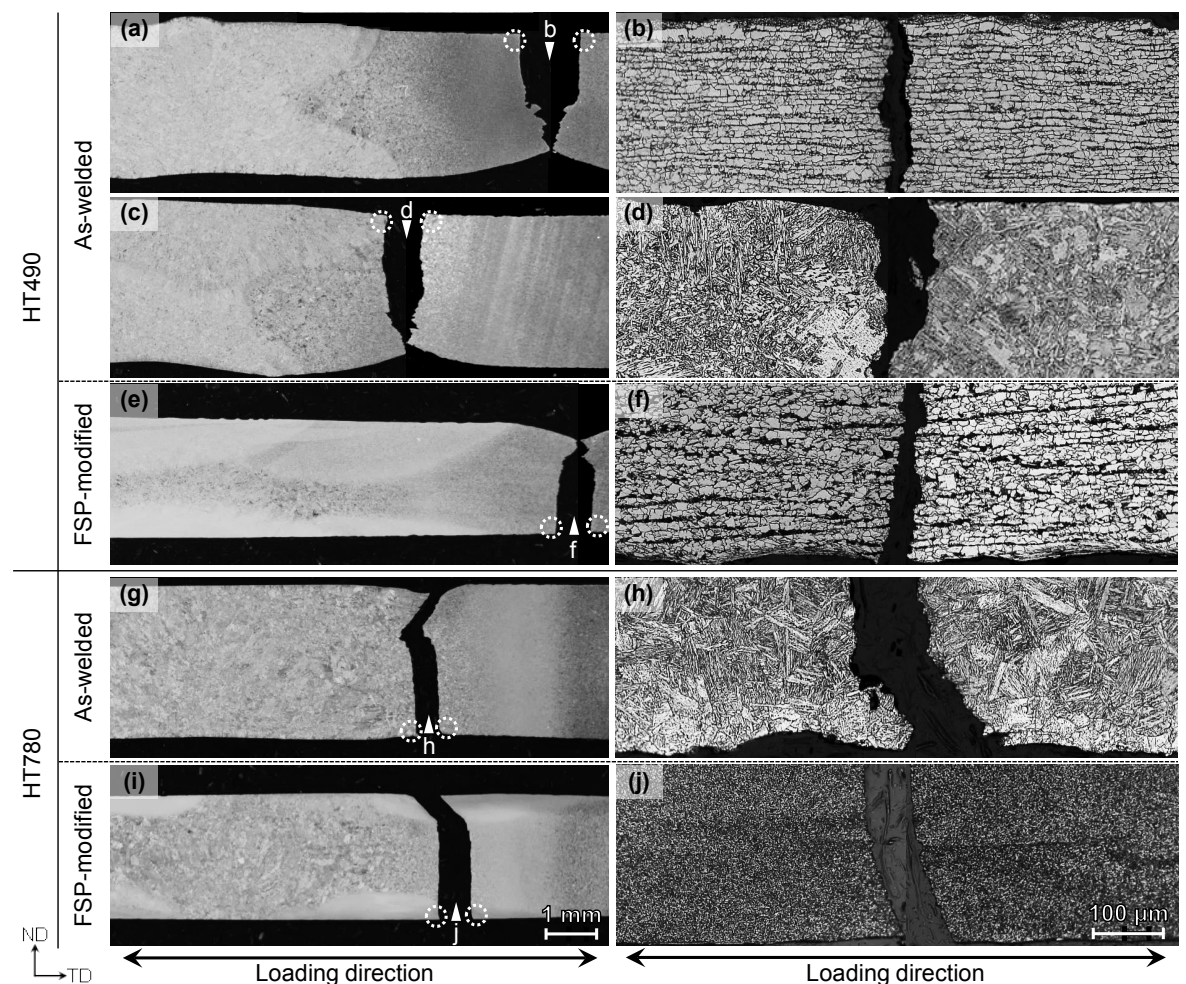

Figure 8. S-N curves of the welded joints w/o and w/FSP for HT490 and HT780 obtained in the four-point bending fatigue tests.
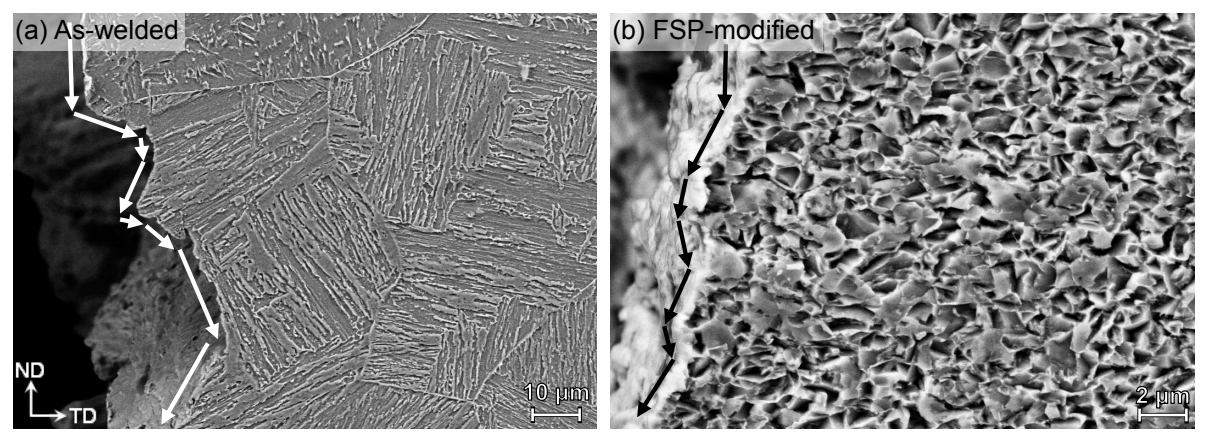

Figure 9. Cross-sectional SEM images beneath the fatigue crack initiation sites on the surface of the welded joints for HT780 (a) w/o and (b) w/FSP in Figure 8(h) and Figure $8(\mathrm{j})$, respectively.

Table 3. Failure location in all fatigue tests.

\begin{tabular}{ccccccccccc}
\hline \multirow{2}{*}{ Specimens } & \multicolumn{7}{c}{ Stress amplitude, $\sigma_{\mathrm{a}} / \mathrm{MPa}$} \\
\cline { 2 - 10 } & & 146 & 158 & 169 & 180 & 191 & 203 & 214 & 225 & 236 \\
\hline \multirow{2}{*}{ HT490 } & As-welded & Not failure & ICHAZ & ICHAZ & CCHAZ & ICHAZ & - & - & - & - \\
& FSP-modified & - & Not failure Not failure & Not failure & BM & - & - & - & - \\
\multirow{2}{*}{ HT780 } & As-welded & - & - & - & Not failure & CGHAZ & CGHAZ & CGHAZ & CGHAZ CGHAZ \\
& FSP-modified & - & - & - & - & Not failure & SZ & SZ & SZ & SZ \\
\hline
\end{tabular}


2) Hardness of the Mn-rich regions was lower than that of the Mn-poor regions in the SZ. The welded joints with FSP for HT490 exhibited higher hardness than that of the BM through whole of the SZ surface, while those for HT780 exhibited the minimum hardness value similar to that of the $\mathrm{BM}$ at the $\mathrm{SZ}$ surface.

3) Fatigue strength increased by about $35 \mathrm{MPa}$ and $15 \mathrm{MPa}$ in stress amplitude at $10^{7}$ cycles as fatigue limit due to FSP. Fatigue failure occurred at the BM and the SZ, respectively, in the welded joints modified by FSP for HT490 and HT780, in comparison with the HAZs in the as-welded joints for both grade steels.

\section{Acknowledgements}

One of the authors, Mr. Yamamoto, gratefully acknowledges the financial support from "Program for Leading Graduate Schools: Interactive Materials Science Cadet Program" in Osaka University. The authors would like to thank Prof./Dr. Hidetoshi Fujii, Joining and Welding Research Institute, Osaka University for supporting FSP operation.

\section{References}

[1] Mishra, R.S. and Ma, Z.Y. (2005) Friction Stir Welding and Processing. Materials Science and Engineering $R$, 50, 1-78. https://doi.org/10.1016/j.mser.2005.07.001

[2] Charit, I. and Mishra, R.S. (2003) High Strain Rate Superplasticity in a Commercial 2024 Al Alloy via Friction Stir Processing. Materials Science and Engineering A, 359, 290-296. https://doi.org/10.1016/S0921-5093(03)00367-8

[3] Yadav, D. and Bauri, R. (2012) Effect of Friction Stir Processing on Microstructure and Mechanical Properties of Aluminium. Materials Science and Engineering A, 539, 85-92. https://doi.org/10.1016/j.msea.2012.01.055

[4] Yuan, W., Panigrahi, S.K. and Mishra, R.S. (2013) Achieving High Strength and High Ductility in Friction Stir-Processed Cast Magnesium Alloy. Metallurgical and Materials Transactions A, 44, 3675-3684. https://doi.org/10.1007/s11661-013-1744-5

[5] Guru, P.R., Khan, F., Panigrahi, S.K. and Janaki Ram, G.D. (2015) Enhancing Strength, Ductility and Machinability of a Al-Si Cast Alloy by Friction Stir Processing. Journal of Manufacturing Processes, 18, 67-74. https://doi.org/10.1016/j.jmapro.2015.01.005

[6] Sekban, D.M., Aktarer, S.M., Xue, P., Ma, Z.Y. and Purcek, G. (2016) Impact Toughness of Friction Stir Processed Low Carbon Steel Used in Shipbuilding. Materials Science and Engineering A, 672, 40-48. https://doi.org/10.1016/j.msea.2016.06.063

[7] Xue, P., Wang, B.B., Chen, F.F., Wang, W.G., Xiao, B.L. and Ma, Z.Y. (2016) Microstructure and Mechanical Properties of Friction Stir Processed $\mathrm{Cu}$ with an Ideal Ultrafine-Grained Structure. Materials Characterization, 121, 187-194. https://doi.org/10.1016/j.matchar.2016.10.009

[8] Ni, D.R., Wang, D., Feng, A.H., Yao, G. and Ma, Z.Y. (2009) Enhancing the High-Cycle Fatigue Strength of Mg-9Al-1Zn Casting by Friction Stir Processing. Scripta Materialia, 61, 568-571. https://doi.org/10.1016/j.scriptamat.2009.05.023 
[9] Kapoor, R., Kandasamy, K., Mishra, R.S., Baumann, J.A. and Grant, G. (2013) Effect of Friction Stir Processing on the Tensile and Fatigue Behavior of a Cast A206 Alloy. Materials Science and Engineering A, 561, 159-166. https://doi.org/10.1016/j.msea.2012.10.090

[10] da Silva, J., Costa, J.M., Loureiro, A. and Ferreira, J.M. (2013) Fatigue Behaviour of AA6082-T6 MIG Welded Butt Joints Improved by Friction Stir Processing. Materials and Design, 51, 315-322. https://doi.org/10.1016/j.matdes.2013.04.026

[11] Borrego, L.P., Costa, J.D., Jesus, J.S., Loureiro, A.R. and Ferreira, J.M. (2014) Fatigue Life Improvement by Friction Stir Processing of 5083 Aluminium Alloy MIG Butt Welds. Theoretical and Applied Fracture Mechanics, 70, 68-74. https://doi.org/10.1016/j.tafmec.2014.02.002

[12] Costa, J.D.M., Jesus, J.S., Loureiro, A., Ferreira, J.A.M. and Borrego, L.P. (2014) Fatigue Life Improvement of Mig Welded Aluminium T-Joints by Friction Stir Processing. International Journal of Fatigue, 61, 244-254. https://doi.org/10.1016/j.ijfatigue.2013.11.004

[13] Jesus, J.S., Costa, J.M., Loureiro, A. and Ferreira, J.M. (2017) Fatigue Strength Improvement of GMAW T-Welds in AA 5083 by Friction-Stir Processing. International Journal of Fatigue, 97, 124-134. https://doi.org/10.1016/j.ijfatigue.2016.12.034

[14] Ye, N. and Moan, T. (2007) Improving Fatigue Life for Aluminium Cruciform Joints by Weld Toe Grinding. Fatigue and Fracture of Engineering Materials and Structures, 31, 152-163. https://doi.org/10.1111/j.1460-2695.2007.01210.x

[15] Baptista, R., Infante, V. and Branco, C.M. (2008) Study of the Fatigue Behavior in Welded Joints of Stainless Steels Treated by Weld Toe Grinding and Subjected to Salt Water Corrosion. International Journal of Fatigue, 30, 453-462. https://doi.org/10.1016/j.ijfatigue.2007.04.011

[16] Fu, Z., Ji, B., Kong, X. and Chen, X. (2017) Grinding Treatment Effect on Rib-toRoof Weld Fatigue Performance of Steel Bridge Decks. Journal of Constructional Steel Research, 129, 163-170. https://doi.org/10.1016/j.jcsr.2016.09.018

[17] Dahle, T. (1998) Design Fatigue Strength of TIG-Dressed Welded Joints in HighStrength Steels Subjected to Spectrum Loading. International Journal of Fatigue, 20, 677-681. https://doi.org/10.1016/S0142-1123(98)00031-0

[18] Ramalho, A.L., Ferreira, J.A.M. and Branco, C.A.G.M. (2011) Fatigue Behaviour of T Welded Joints Rehabilitated by Tungsten Inert Gas and Plasma Dressing. Materials and Design, 32, 4705-4713. https://doi.org/10.1016/j.matdes.2011.06.051

[19] Skriko, T., Ghafouri, M. and Björk, T. (2017) Fatigue Strength of TIG-Dressed Ultra-High-Strength Steel Fillet Weld Joints at High Stress Ratio. International Journal of Fatigue, 94, 110-120. https://doi.org/10.1016/j.ijfatigue.2016.09.018

[20] Wang, T., Wang, D.P., Huo, L.X. and Zhang, Y.F. (2009) Discussion on Fatigue Design of Welded Joints Enhanced by Ultrasonic Peening Treatment (UPT). International Journal of Fatigue, 31, 644-650. https://doi.org/10.1016/j.ijfatigue.2008.03.030

[21] Sakino, Y., Sano, Y., Sumiya, R. and Kim, Y.-C. (2012) Major Factor Causing Improvement in Fatigue Strength of Butt Welded Steel Joints after Laser Peening without Coating. Science and Technology of Welding and Joining, 17, 402-407. https://doi.org/10.1179/1362171812Y.0000000022

[22] Berg, J. and Stranghöner, N. (2016) Fatigue Behaviour of High Frequency Hammer Peened Ultra High Strength Steels. International Journal of Fatigue, 82, 35-48. https://doi.org/10.1016/j.ijfatigue.2015.08.012

[23] Kang, H.T., Lee, Y.-L. and Sun, X.J. (2008) Effects of Residual Stress and Heat Treatment on Fatigue Strength of Weldments. Materials Science and Engineering A, 
497, 37-43. https://doi.org/10.1016/j.msea.2008.06.011

[24] Ito, K., Okuda, T., Ueji, R., Fujii, H. and Shiga, C. (2014) Increase of Bending Fatigue Resistance for Tungsten Inert Gas Welded SS400 Steel Plates Using Friction Stir Processing. Materials and Design, 61, 275-280.

https://doi.org/10.1016/j.matdes.2014.04.076

[25] Motoyashiki, Y., Bruckner-Foit, A. and Sugeta, A. (2008) Microstructural Influence on Small Fatigue Cracks in a Ferritic-Martensitic Steel. Engineering Fracture Mechanics, 75, 768-778. https://doi.org/10.1016/j.engfracmech.2007.04.019 